\title{
Dissertações e teses do PPGCI-UFMG: avaliando a sintonia temática internacional das pesquisas em Arquivologia
}

\author{
Renato Pinto Venancio \\ Cintia Aparecida Chagas ${ }^{I I}$ \\ https://orcid.org/0000-0002-7111-510X \\ Adalson de Oliveira Nascimento ${ }^{\text {III }}$ \\ https://orcid.org/0000-0002-4859-4544
}

Ivana D. Parrela ${ }^{I V}$

\footnotetext{
IUniversidade Federal de Minas Gerais, Belo Horizonte, MG, Brasil. Professor do PPGCI/UFMG. Doutor em História - Paris IV.

Pesquisador do CNPq-1D.

${ }^{I I}$ Universidade Federal de Minas Gerais, Belo Horizonte, MG, Brasil. Professora do PPGCI/UFMG. Doutora em Ciência da Informação - UFMG.

${ }^{I I I}$ Universidade Federal de Minas Gerais, Belo Horizonte, MG, Brasil. Professor do PPGCI/UFMG. Doutor em Educação - UFMG.

${ }^{I V}$ Universidade Federal de Minas Gerais, Belo Horizonte, MG, Brasil. Professora do PPGCI/UFMG. Doutora em História - UFMG.
}

http://dx.doi.org/10.1590/1981-5344/3894

Este texto discute, a partir de metodologia proposta por pesquisadores canadenses, a sintonia temática entre as teses e dissertações defendidas no Programa de PósGraduação em Ciência da Informação da Universidade Federal de Minas Gerais e a produção internacional da área de Arquivologia, visando proporcionar mais uma ferramenta para identificar o grau de internacionalização desse programa.

Palavras-chave: Arquivologia. Produção acadêmica. Pesquisa científica. Programa de Pós-Graduação em Ciência da Informação. 


\section{PPGCI-UFMG dissertations and theses: Archival Science issues and alignment with international studies}

The present study aims at identifying, based on the methodology proposed by Canadian scholars, the thematic alignment of Master's and Doctorate programs offered by the Federal University of Minas Gerais (UFMG) Graduate Program in Information Science (PPGCI) with international scientific production in the realm of Archival Science. Therefore, it is also intended to provide a tool for identification of the degree of internationalization of such Program and to point out shortcomings in the set of the issues investigated alongside new directions in alumni and scholars' research.

Keywords: Archival Science. Academic production. Scientific research. Graduate Program in Information Science.

\section{Introdução}

A internacionalização é uma importante característica e critério de avaliação dos programas de pós-graduação. De acordo com o documento de área Ciências Sociais Aplicadas I, compreendendo Comunicação, Ciência da Informação e Museologia (atual Comunicação e Informação), o significado de "internacionalização" não é unívoco. Esse critério envolve, pelo menos, três componentes: universidades, produção científica e pesquisadores (BRASIL. Ministério da Educação, 2016).

Recente avaliação dos programas de pós-graduação recomendou o emprego dos seguintes indicadores de internacionalização (MIGLINO, 2017):

a) participação de discentes estrangeiros no PPG e de discentes nacionais em programas de formação na modalidade "sanduíche";

b) participação de docentes e discentes em coautoria internacional;

c) publicação de livros por editores em nível mundial; 
d) participação de docentes nos conselhos editoriais de revistas científicas qualificadas e de impacto representativo;

e) participação de docentes em comitês de programas de conferências internacionais qualificados e representativos da área;

f) programas de cotutela (dupla diplomação) com instituições estrangeiras;

g) existência de site do PPG em pelo menos dois idiomas;

h) apoio logístico do PPG/IES para o recebimento de alunos e pesquisadores estrangeiros;

i) número de professores palestrantes convidados em eventos internacionais;

j) número de professores com participação em bancas de doutorado em instituições no exterior;

k) ofertas de disciplinas em outro idioma no PPG;

I) inclusão de uma avaliação qualitativa de membros representativos da área no exterior;

m)número de professores visitantes estrangeiros com financiamento externo;

n) capacidade de captação de recursos de agências internacionais de fomento (ou bilaterais); e

o) prêmios internacionais.

Todos esses indicadores são relevantes e servem para medir o impacto da internacionalização. No entanto, não contemplam um dos aspectos mais relevantes de um programa de pós-graduação: sua sintonia em relação ao debate científico e tecnológico internacional. Em outras palavras, os indicadores citados não levam em conta os conteúdos das teses e dissertações nem a incorporação nelas de conteúdos de pesquisas internacionais, aspectos relevantes para o desenvolvimento da sociedade brasileira.

Este texto adota metodologia proposta por grupo de pesquisa da Universidade de Montreal, Canadá, que visa identificar os principais temas da investigação internacional da área de Arquivologia. Procura avaliar em que medida o Programa de Pós-Graduação em Ciência da Informação (PPGCI) da Universidade Federal de Minas Gerais (UFMG), no âmbito do referido campo de pesquisa, está efetivamente internacionalizando. O indicador utilizado para tal avaliação considera o conteúdo das dissertações e teses produzidas. Antes de avançar nesse sentido, apresentam-se a origem e o contexto em que essas pesquisas foram desenvolvidas. 


\section{PPGCI da Escola de Ciência da Informação da UFMG}

O Programa de Pós-Graduação em Ciência da Informação da UFMG teve origem no Curso de Pós-Graduação em Biblioteconomia, em 1976, o qual resultou dos esforços da Coordenação de Aperfeiçoamento de Pessoal de Nível Superior (CAPES) para formar profissionais na área de Biblioteconomia, visando dar suporte às pós-graduações criadas em grande número nas duas décadas anteriores. Foi o segundo curso de mestrado em Biblioteconomia/Ciência da Informação, de um total de cinco. Tinha como área de concentração a Administração de Bibliotecas. Entendia-se que tais cursos funcionariam como difusores de inovações e de qualificação profissional de bibliotecários por meio da pesquisa (VIEIRA, 1990).

Em 1991, o curso foi reestruturado. A ênfase transferiu-se da instituição biblioteca para o "fenômeno informação". Nas palavras de Paim (2000), "a opção norteadora do projeto de reestruturação centra-se, pois, na informação enquanto bem e direitos sociais, instrumento de poder e de estratégias e enquanto bem de produção, criando espaço para que se estudem variados tipos de informação e os contextos de sua ocorrência" (PAIM, 2000, p. 105-106). A reestruturação acarretou a mudança do nome do curso para "Curso de Pós-Graduação em Ciência da Informação", expressando o novo objeto e a nova identidade. A área de concentração passou a ser Organização da Informação. Paim (2000) registra a diversificação das áreas de formação dos candidatos ao curso e seu expressivo aumento quantitativo após a reformulação.

Em 1997, criou-se o curso de doutorado, que acarretou o incremento de recursos humanos e o crescimento da produção cientifica do então "Programa de Pós-Graduação em Ciência da Informação" (PAIM, 2000). De imediato, a área de concentração passou a ser Produção, Organização e Utilização da Informação.

Em 2016, o PPGCI-UFMG passou por nova reformulação, passando a área de concentração a denominar-se "Informação, Mediações e Cultura". As linhas de pesquisa passaram a ser: Memória social, patrimônio e produção do conhecimento; Políticas públicas e organização da informação; Usuários, gestão do conhecimento; e Práticas informacionais. Também, entrou em funcionamento o Programa de Pós-Graduação em Gestão e Organização do Conhecimento na Escola (PPGGOC-UFMG), sediado na Escola de Ciência da Informação da UFMG.

A reestruturação do PPGCI-UFMG e a criação do PPGGOC-UFMG, em 2016, foram fruto da ampliação e consolidação da variedade de visões e de temáticas sobre a Ciência da Informação na UFMG. O funcionamento do curso de graduação de Arquivologia, em 2009, e do de Museologia, em 2010, na ECI-UFMG contribuiu para tal diversificação de temáticas.

Levantamento de Cendón e Dumont (2015, p. 15), entre 1976 e 2015, revela que foram defendidas 135 teses e 428 dissertações no PPGCI-UFMG e que o desenvolvimento de pesquisas sobre Arquivologia 
ocorreu a partir da década de 1990, coincidindo com a consolidação da atuação do Programa no campo da Informação.

\section{Dissertações e teses do PPGCI em Arquivística}

O conjunto de dissertações e teses a ser analisado diz respeito ao período compreendido entre 1990 e 2017. Apesar de o PPGCI ser anterior a essa data, esse recorte temporal foi contemplado em razão do interesse em se comparar a produção desse programa com a produção internacional na área de Arquivística, identificada por Carol Couture e Marcel Lajeunesse. Para efetuar essa comparação, apresentam-se informações sumárias sobre as pesquisas do PPGCI no referido período.

\section{Quadro 1 - Dissertações de mestrado}

\begin{tabular}{|c|c|c|c|}
\hline & Autor & Título & Ano \\
\hline 1 & $\begin{array}{l}\text { Vera Maria R. Vasconcellos } \\
\text { Motta }\end{array}$ & $\begin{array}{c}\text { "Arquivos privados de titulares mineiros - 1930/1983: } \\
\text { um estudo sobre a localização, composição e uso dos } \\
\text { documentos" }\end{array}$ & 1993 \\
\hline 2 & $\begin{array}{l}\text { Maria do Carmo Alvarenga e } \\
\text { Gomes }\end{array}$ & $\begin{array}{c}\text { "A produção do conhecimento histórico e do } \\
\text { documento: estudo da relação entre a historiografia } \\
\text { mineira e as fontes" }\end{array}$ & 1994 \\
\hline 3 & $\begin{array}{l}\text { Maria Regina Persechini A. } \\
\text { Cortês }\end{array}$ & $\begin{array}{l}\text { "Arquivo público e informação: acesso à informação } \\
\text { nos arquivos públicos estaduais do Brasill" }\end{array}$ & 1996 \\
\hline 4 & Marta Eloísa Melgaço Neves & $\begin{array}{l}\text { "Em busca da organicidade: um estudo do fundo da } \\
\text { Secretaria de governo da capitania de Minas Gerais" }\end{array}$ & 1997 \\
\hline 5 & Cláudia Resende Silva & $\begin{array}{l}\text { "Senado da Câmara da Vila de São João Del Rei: da } \\
\text { administração colonial à pesquisa histórica" }\end{array}$ & 2000 \\
\hline 6 & Beatriz Junqueira Pedras & $\begin{array}{c}\text { "Uma leitura do I Livro de Tombo do Convento do } \\
\text { Carmo em Salvador: contribuição à construção } \\
\text { histórica da Ordem dos Carmelitas na Bahia - } \\
\text { colonial" }\end{array}$ & 2000 \\
\hline 7 & André Henrique Guerra Cotta & $\begin{array}{l}\text { "O tratamento da informação em acervos de } \\
\text { manuscrito musicais brasileiros" }\end{array}$ & 2000 \\
\hline 8 & Emília Barroso Cruz & $\begin{array}{c}\text { "Memória governamental e utilização de documentos } \\
\text { eletrônicos pela administração pública no Brasil: o } \\
\text { caso da Secretaria de Estado da Fazenda de Minas } \\
\text { Gerais" }\end{array}$ & 2002 \\
\hline 9 & Maria Cristina Vieira de Freitas & $\begin{array}{c}\text { "Tudo passa e tudo fica no caminho que se faz: Um } \\
\text { estudo qualitativo de acervo e fundo de arquivo de } \\
\text { instituição cultural, sob o paradigma que insere a } \\
\text { Arquivologia no contexto de uma ciência da } \\
\text { informação" }\end{array}$ & 2003 \\
\hline 10 & $\begin{array}{l}\text { Ana Márcia Lutterbach } \\
\text { Rodrigues }\end{array}$ & "Uma análise da teoria dos arquivos" & 2004 \\
\hline 11 & Agnaldo Lopes Martins & $\begin{array}{l}\text { "Metadados para descrição de documentos } \\
\text { remanescentes de fundo eclesiástico" }\end{array}$ & 2006 \\
\hline 12 & Leandro Ribeiro Negreiros & $\begin{array}{l}\text { "Sistemas eletrônicos de gerenciamento de } \\
\text { documentos arquivísticos: Um questionário para } \\
\text { escolha, aplicação e avaliação" }\end{array}$ & 2007 \\
\hline 13 & Shirlene Linny da Silva & $\begin{array}{l}\text { "Construindo o direito de acesso aos arquivos da } \\
\text { repressão: O caso do Departamento de Ordem Política } \\
\text { e Social de Minas Gerais" }\end{array}$ & 2007 \\
\hline 14 & Alessandro Ferreira Costa & $\begin{array}{c}\text { "Gestão arquivística na era do cinema digital: } \\
\text { formação de acervos de documentos digitais provindos } \\
\text { da prática cinematográfica" }\end{array}$ & 2007 \\
\hline 15 & Silvana Aparecida Silva dos & "Ontologias como domínio conceitual e planos de & 2010 \\
\hline
\end{tabular}


Dissertações e teses do PPGCI-UFMG: avaliando a sintonia temática internacional das pesquisas em Arquivologia
Renato Pinto Venancio; Cintia Aparecida Chagas; Adalson de Olivera Nascimento;

\begin{tabular}{|c|c|c|c|}
\hline & Santos & $\begin{array}{l}\text { classificação arquivística: um estudo de caso sobre } \\
\text { instituições federais de ensino superior" }\end{array}$ & \\
\hline 16 & Leonardo Mendes Padilha & $\begin{array}{c}\text { "Metadados para preservação digital na organização } \\
\text { arquivística" }\end{array}$ & 2010 \\
\hline 17 & Simone Torres & $\begin{array}{c}\text { "A caracterização do documento jurídico para a } \\
\text { organização da informação" }\end{array}$ & 2013 \\
\hline 18 & Luiz Carlos da Silva & $\begin{array}{l}\text { "Políticas públicas de arquivo: a gestão documental do } \\
\text { Arquivo Público do Estado do Espírito Santo" }\end{array}$ & 2013 \\
\hline 19 & $\begin{array}{c}\text { Gabrielle Francinne de Souza } \\
\text { Carvalho Tanus }\end{array}$ & $\begin{array}{c}\text { "Cenário acadêmico-institucional dos cursos de } \\
\text { Arquivologia, Biblioteconomia e Museologia do } \\
\text { Brasil" }\end{array}$ & 2013 \\
\hline 20 & Wendell Lopes de Assis & $\begin{array}{l}\text { "Arquivos Legislativos: a política pública arquivística } \\
\text { em instituições legislativas municipais" }\end{array}$ & 2015 \\
\hline 21 & Clausi Maria do Porto Gomes & $\begin{array}{c}\text { "Centros de memória acadêmicos: um estudo de } \\
\text { multicasos na UFMG" }\end{array}$ & 2015 \\
\hline 22 & Gláucia Aparecida Vaz & $\begin{array}{c}\text { "A importância dos estudos de usuários na formação } \\
\text { do arquivista" }\end{array}$ & 2015 \\
\hline 23 & Aline de Queiroz Lopes & $\begin{array}{l}\text { "Reflexões arquivísticas no processo de gestão de } \\
\text { documentos de imagens em movimento produzidos } \\
\text { e/ou recolhidos em virtude da atividade fim de uma } \\
\text { emissora de televisão" }\end{array}$ & 2016 \\
\hline 24 & Rubem Damião Soares Nogueira & $\begin{array}{c}\text { "Conexões entre Arquivo, Biblioteca e Museu: } \\
\text { similaridade das atividades profissionais e colaboração } \\
\text { entre instituições" }\end{array}$ & 2016 \\
\hline 25 & Thiara dos Santos Alves & $\begin{array}{c}\text { "Classificação Brasileira de Ocupações: Arquivistas e } \\
\text { Museólogos" }\end{array}$ & 2016 \\
\hline 26 & Thais Nodare de Oliveira & $\begin{array}{c}\text { "Os Centros de memória e documentação da } \\
\text { Universidade Federal de Minas Gerais: perfis } \\
\text { institucionais e políticas de acervo" }\end{array}$ & 2016 \\
\hline 27 & Maristela Costa Martiniano & $\begin{array}{l}\text { "O Arquivo Público da cidade de Belo Horizonte } \\
\text { como campo etnográfico: vestígios do africanismo no } \\
\text { arquivo pessoal de Nelson Coelho de Senna" }\end{array}$ & 2017 \\
\hline 28 & Maria Juliana Nunes da Silva & $\begin{array}{c}\text { "Entre a teoria e a prática: o contexto de atuação dos } \\
\text { estagiários, sob a ótica das instituições contratantes e } \\
\text { dos egressos do curso de Arquivologia da } \\
\text { Universidade Federal de Minas Gerais" }\end{array}$ & 2017 \\
\hline 29 & Bruno Gomes da Silveira & $\begin{array}{c}\text { "Preservação digital dos processos judiciais } \\
\text { eletrônicos: políticas públicas de arquivo no Tribunal } \\
\text { Regional do Trabalho da Terceira Região, Minas } \\
\text { Gerais" }\end{array}$ & 2017 \\
\hline & \multicolumn{3}{|c|}{$\begin{array}{l}\text { Fonte: Dados da pesquisa. Disponível em: } \\
\text { <http://catalogodeteses.capes.gov.br/catalogo-teses/\#!/> e } \\
\text { <http://www.bibliotecadigital.ufmg.br/dspace>. Acesso em: } 22 \text { nov. } 2018 .\end{array}$} \\
\hline & Autor & Título & Ano \\
\hline 1 & Kátia de Pádua Thomaz & $\begin{array}{l}\text { "A preservação de documentos eletrônicos de caráter } \\
\text { arquivístico: Novos desafios, velhos problemas" }\end{array}$ & 2004 \\
\hline 2 & Nádina Aparecida Moreno & $\begin{array}{l}\text { "A informação arquivística no processo de tomada de } \\
\text { decisão em organizações universitárias" }\end{array}$ & 2006 \\
\hline 3 & Delfim Afonso Júnior & $\begin{array}{l}\text { "Imagens de arquivo, cenas desconhecidas: um estudo } \\
\text { sobre Bibliotecários, Jornalistas, rede de relações e } \\
\text { práticas informacionais em arquivos de } \\
\text { Telejornalismo" }\end{array}$ & 2008 \\
\hline 4 & Célia da Consolação Dias & $\begin{array}{c}\text { "Análise de domínio organizacional na perspectiva } \\
\text { arquivística: potencialidade no uso da metodologia } \\
\text { DIRKS - Designing and Implementing Recordkeeping } \\
\text { Systems" }\end{array}$ & 2010 \\
\hline
\end{tabular}




\begin{tabular}{|c|c|c|c|}
\hline 5 & Rosa Zuleide Lima da Silva & $\begin{array}{l}\text { "Representação temática da Arquivologia com base na } \\
\text { classificação facetada" }\end{array}$ & 2013 \\
\hline 6 & $\begin{array}{l}\text { Ana Marcia Lutterbach } \\
\text { Rodrigues }\end{array}$ & $\begin{array}{l}\text { "A construção de uma política nacional de arquivos: } \\
\text { bases conceituais, ações e problemas" }\end{array}$ & 2013 \\
\hline 7 & $\begin{array}{l}\text { José Alimatéia de Aquino } \\
\text { Ramos }\end{array}$ & $\begin{array}{l}\text { "As possibilidades de aproximação e diálogo entre } \\
\text { Arquivologia, Biblioteconomia e Museologia via } \\
\text { modelo formativo: o caso da ECI-UFMG" }\end{array}$ & 2013 \\
\hline 8 & Leonardo Vasconcelos Renault & "O ato colecionador" & 2015 \\
\hline 9 & $\begin{array}{c}\text { Cintia Aparecida Chagas } \\
\text { Arreguy }\end{array}$ & $\begin{array}{l}\text { "Arquivo Público da Cidade de Belo Horizonte: a } \\
\text { função avaliação no contexto de políticas públicas } \\
\text { arquivísticas municipais no Brasil" }\end{array}$ & 2016 \\
\hline 10 & Welder Antônio Silva & $\begin{array}{l}\text { "Exceções legais ao direito de acesso à informação: } \\
\text { dimensões contextuais das categorias de informação } \\
\text { pessoal nos documentos arquivísticos" }\end{array}$ & 2017 \\
\hline 11 & Sheila Margareth Teixeira Adão & $\begin{array}{c}\text { "1ª CNARQ: a Conferência Nacional de Arquivos e a } \\
\text { construção de uma política nacional para os arquivos } \\
\text { brasileiros" }\end{array}$ & 2017 \\
\hline
\end{tabular}

Fonte: Dados da pesquisa. Disponível em:

<http://catalogodeteses.capes.gov.br/catalogo-teses/\#!/> e

<http://www.bibliotecadigital.ufmg.br/dspace>. Acesso em: 22 nov. 2018.

Esse levantamento, realizado no Portal de Teses e Dissertações da Capes (http://catalogodeteses.capes.gov.br/catalogo-teses/\#!/), utilizando o indexador "Arquivologia", foi posteriormente ampliado e corrigido, a partir dos dados do PPGCI-UFMG. Apontou que 40 dissertações e teses sobre Arquivologia foram defendidas nesse programa de pós-graduação em Ciência da Informação entre 1990 e 2017.

Para avaliar o significado da produção da UFMG, salienta-se que, segundo o Portal da CAPES, 204 dissertações e teses com interface na área de Arquivologia foram defendidas no Brasil entre 1990 e 2017. Embora esse número seja passível de discussão (como nos casos de programas de pós-graduação em Engenharia, Letras, Psicologia ou Arquitetura que declararam ter produzido dissertações e teses sobre Arquivologia), ele serve de ordem de grandeza para comparar com a produção da UFMG. Em outras palavras, nas últimas três décadas cerca de $20 \%$ das pesquisas em Arquivologia no âmbito das pós-graduações brasileiras ocorreram no PPGCI-UFMG. Trata-se, portanto, de um programa representativo e de uma amostragem relevante da produção nacional.

A tese de Maria Odila Fonseca, "Arquivologia e Ciência da Informação: (re)definição de marcos interdisciplinares", defendida em 2004, já apontava o PPGCI-UFMG como um dos programas com maior número de dissertações e teses na área de Arquivologia. A pesquisa de Fonseca, também realizada no portal da Capes, indicou a existência de 53 trabalhos produzidos entre 1992 e 2001 com os indexadores "Arquivologia" e "Arquivística" em todo o Brasil. Os trabalhos foram defendidos em programas de pós-graduação de diversas áreas. O PPGCIUFMG era então o quinto programa com o maior número de trabalhos: 18. Fonseca apurou que oito professores orientaram mais de um trabalho 
sobre Arquivologia. O PPGCI-UFMG foi o único programa que contava dois professores nesse levantamento ${ }^{1}$, contra um dos demais.

A pesquisa de Maria Odila $\mathrm{K}$. Fonseca indica que, no início dos anos 2000, o PPGCI-UFMG foi um dos programas que mais produziu dissertações e teses na área de Arquivologia. Desde então, a produção cresceu, chegando a cerca de $20 \%$ da produção nacional. Talvez esse aumento esteja associado ao início do funcionamento do curso de graduação em Arquivologia, em 2009, e ao processo de criação da Diretoria de Arquivos Institucionais, em 2012. Estes dois fatores ampliaram a comunidade que se dedica à área de Arquivologia e podem ter contribuído para impulsionar ainda mais a pesquisa sobre a temática no PPGCI-UFMG.

\section{Avaliação da pesquisa científica em Arquivologia: uma metodologia}

O grupo de pesquisa liderado por Carol Couture e Marcel Lajeunesse, professores da École de bibliothéconomie et des sciences de I'information (EBSI), da Universidade de Montréal, desenvolveu metodologia para identificar a produção científica na área de Arquivologia. A primeira versão, apresentada na forma de relatório de pesquisa (COUTURE, 1999), baseou-se no levantamento de artigos publicados em 60 periódicos científicos e teve grande repercussão, balizando discussões no International Council on Archives (ICA), assim como dando origem a uma série de artigos (COUTURE, 2001; 2002; COUTURE; DUCHARME, 2005). A partir de 2000, esse mesmo grupo de pesquisa aplicou tal metodologia para classificar disciplinas dos cursos de Arquivologia e projetos de pesquisa de professores e de doutorandos de programas de pós-graduação.

Em 2014, divulgou-se um novo balanço da pesquisa, que se consistiu em um levantamento abrangente, cobrindo mais de uma década, relativo à produção científica em 46 instituições de ensino superior em Arquivologia, distribuídas em todos os continentes, exceto Oceania e Antártida (COUTURE; LAJEUNESSE, 2014, p. 213).

O resultado desse segundo levantamento agregou novos temas à proposta de 1999, dando origem aos seguintes critérios de classificação:

1) objeto e finalidade da arquivística - pesquisas que procuram identificar o uso e a utilidade dos arquivos;

2) arquivo e sociedade - estudo da função social do arquivista e da Arquivologia enquanto área científica;

3) história dos arquivos e da arquivística - formação do campo de conhecimento e das instituições arquivísticas;

4) funções arquivísticas - pesquisa das funções arquivísticas de produção de documentos, classificação, avaliação,

\footnotetext{
${ }^{1}$ Professora Lucy Gonçalves Fontes e professora Vilma Moreira dos Santos.
} 
aquisição/recolhimento, preservação, descrição e difusão/acesso;

5) gestão de programas e de serviços de arquivo - teoria e prática, gestão e planejamento, contabilidade e finança de arquivos, arquitetura de arquivos, implantação de serviços arquivísticos e marketing arquivístico;

6) tecnologia - informática aplicada aos arquivos e sistemas e redes;

7) suportes e tipos de arquivos - documentos textuais, documentos audiovisuais, documentos iconográficos documentos eletrônicos e outros suportes documentais;

8) instituições arquivísticas - arquivos públicos (nacional, regional e local), instituições de ensino de Arquivologia, arquivos de instituições religiosas, arquivos de instituições científicas, arquivos de instituições financeiras, comercias e industriais e outros tipos de instituições arquivísticas;

9) problemas particulares dos arquivos - ética arquivística/sigilo e acesso à informação, arquivo e meio ambiente, legislação arquivística e políticas nacionais de arquivo; e

10) Outros temas - temas gerais, tratamento de fundos arquivísticos e pesquisas históricas (COUTURE; LAJEUNESSE, 2014, p. 262-264).

Essa classificação é uma adaptação, que procurou viabilizar a comparação entre os dois períodos da pesquisa. Couture e Lajeunesse ressaltam a existência de temas não contemplados no esquema acima, como aqueles decorrentes da influência do pós-modernismo na Arquivologia. Essa nova perspectiva tem promovido uma crescente aproximação entre a Arquivologia e a Filosofia, assim como com a Antropologia e a Sociologia. Constata-se, por exemplo, o surgimento de propostas de etnografias das práticas arquivísticas e de programas de pesquisa sobre a sociologia e política de conservação de documentos ou sobre as redes de sociabilidade criadas a partir do uso dos documentos de arquivo. Citam-se como exemplo o crescente uso dos documentos de arquivo pela arte contemporânea e o surgimento da psicogenealogia, método empregado por psicólogos para reconstruir identidades a partir de documentos genealógicos de arquivo entre refugiados de guerra que vivenciaram rupturas traumáticas com a sociedade de origem (SERVAIS; MIRGUET, 2015, p. 7).

Outra abordagem que tem se destacado nas últimas duas décadas prende-se à "globalização da arquivística" ("Mondialisation de l'archivistique"), perspectiva voltada para a pesquisa da condição póscolonial e, também, para o estudo das incorporações nacionais das terminologias e modelos descritivos, aproximando-se das discussões a 
respeito das etnometodologias. Esses novos temas, apesar de relevantes, não foram incorporados à classificação acima. Couture e Lajeunesse (2014) alegam que eles estavam ausentes das preocupações da década de 1990, não servindo, portanto, como elementos de comparação.

Outra dimensão a ser sublinhada é que a diversidade temática das pesquisas em Arquivologia decorre da multiplicidade de arranjos institucionais e de opções teóricas de formação superior. Das 46 instituições identificadas pela pesquisa em foco, apenas 15 (32,6\%) se autodefinem como escolas ou faculdades de Information Science, Information Studies ou School of Information. Na Alemanha, por exemplo, há o curso de Arquivologia oferecido na cidade de Marbur, vinculado à instituição autônoma, a Archivschule, cujo site institucional em inglês traduz tal denominação como Archives School. Na Holanda, a renomada Universidade de Amsterdã segue nomenclatura semelhante, definindo-se como Archiefschool. Em Varsóvia, Polônia, essa formação ocorre em departamentos de história. O mesmo é registrado em Moscou, Rússia. Na Bélgica, o curso de Arquivologia é ofertado pela Faculté de philosophie, arts et letres, na Universidade de Louvain-La-Neuve. Na França, esse tipo de formação ocorre no Département archives et médiathèque, em Toulouse, ou na École des Chartes, instituição autônoma e sediada em Paris. Na Universidad de Salamanca, Espanha, a formação dos arquivistas está vinculada ao Departamento de Biblioteconomía y Documentación. Em Milão, Itália, essa incumbência cabe à Scuola di archivistica, paleografia e diplomática. Em Dublin, Irlanda, constata-se a formação dos arquivistas na School of History and Archives. Em Liverpool, Inglaterra, isso ocorre na School of Histories, Languages and Cultures (COUTURE, LAJEUNESSE, 2014, p. 251-253).

Tal diversidade também é observada fora da Europa. No Canadá, a Université Laval oferece graduação em Arquivologia no Département d'Histoire; na capital do México, na Escuela Nacional de Biblioteconomia y Archivonomia; em Hanoi, Vietnã, na Faculdade de Arquivos e Gestão Administrativa; e na China, em Wuhan, no Departamento de Arquivos e Informação Governamental. Portanto, as áreas de interesse e de interface da Arquivologia não são evidentes, variando muito de país a país, de continente a continente. Constata-se, ainda, uma variação de região a região. Tendo em vista a procedência dos pesquisadores que desenvolveram a classificação acima apresentada, o levantamento mais completo que eles realizaram diz respeito ao Canadá. Nesse país, a formação de arquivista se dá na área de História, como em Laval; nos departamentos de História da Université du Québec à Montréal e da University of Manitoba, em Winnipeg; na School of Library, Archival and Information Studies, da University of British Columbia, em Vancouver; e na Faculty of Information, em Toronto. Estes dois últimos cursos seguem o modelo dos Estados Unidos, onde a formação dos arquivistas ocorre preferencialmente nas faculdades de Biblioteconomia e Ciência da Informação. O mesmo ocorre no Brasil, como afirmam os pesquisadores canadenses: "Les programmes d'archivistique dans ce pays sont 
principalement alignés sur le modèle 'sciences de l'information', et ce, depuis les années 1970" (COUTURE; LAJEUNESSE, 2014, p. 251-253).

Portanto, dependendo da instituição, a pesquisa arquivística na pósgraduação pode voltar-se mais para temas das ciências humanas e sociais ou para áreas de ciência da informação e da computação. Isso não representa um empobrecimento da área e talvez explique a grande diversidade e abrangência dos estudos realizados.

A Tabela 1 lista os temas de pesquisas arquivísticas realizadas em programas internacionais de pós-graduação e no PPGCI-UFMG. Em razão de Couture e Lajeunesse não indicarem números absolutos, citam-se apenas os percentuais identificados por eles, para uma comparação, em termos percentuais, com o perfil temático das 40 dissertações e teses produzidas pelo PPGCI da UFMG.

Tabela 1 - Percentual de temas de pesquisas arquivísticas em programas internacionais de pós-graduação e na PPGCI-UFMG, 1990-2017

\begin{tabular}{l|c|c}
\multicolumn{1}{c|}{ Tema } & $\begin{array}{c}\text { Pós-Graduação } \\
\text { (46 instituições internacionais) }\end{array}$ & $\begin{array}{c}\text { PPGCI- } \\
\text { UFMG }\end{array}$ \\
\hline \hline Objeto e finalidade da arquivística & 7,0 & 12,5 \\
\hline Arquivo e sociedade & 4,0 & 12,5 \\
\hline História dos arquivos e da arquivística & 5,0 & - \\
\hline Funções arquivísticas & 10,0 & 15,0 \\
\hline Gestão de programas e de serviços de arquivo & 11,0 & 2,5 \\
\hline Tecnologia & 24,0 & 5,0 \\
\hline Suportes e tipos de arquivos & 22,0 & 7,5 \\
\hline Instituições arquivísticas & 14,0 & - \\
\hline Problemas particulares dos arquivos & 2,0 & 25,0 \\
\hline Outros & 1,0 & 20,0 \\
\hline
\end{tabular}

Fonte: Dados da pesquisa. Disponível em:

<http://catalogodeteses.capes.gov.br/catalogo-teses/\#!/>;

<http://www.bibliotecadigital.ufmg.br/dspace>. Acesso em: 22 nov. 2018 e COUTURE; LAJEUNESSE (2014).

Os resultados apresentados na Tabela 1 revelam uma produção abrangente do PPGCI no campo da Arquivologia. No entanto, algumas lacunas e contrastes chamam a atenção. Os temas referentes aos 
objetivos da Arquivologia e a relação entre arquivo e sociedade, no cenário internacional, são mais frequentes do que no caso brasileiro. Exemplos da produção do PPGCI nesse tema são a dissertação "Arquivos privados de titulares mineiros - 1930/1983: um estudo sobre a localização, composição e uso dos documentos" e a tese "A informação arquivística no processo de tomada de decisão em organizações universitárias". Já o estudo da história dos arquivos e da arquivística, embora desperte certo interesse internacional, é inexistente no PPGCI. As funções arquivística, tema fundador e intrínseco da área, felizmente, desperta relevante interesse nacional, como no caso da dissertação "Preservação digital dos processos judiciais eletrônicos: políticas públicas de arquivo no Tribunal Regional do Trabalho da Terceira Região", que aborda a função preservação, e da tese "Arquivo Público da Cidade de Belo Horizonte: a função avaliação no contexto de políticas públicas arquivísticas municipais no Brasil", sobre a função avaliação.

Gestão de Programas e de Serviços de Arquivos é uma área carente no PPGCI, encontrando-se apenas uma tese identificada com um perfil próximo a esse tema: "Análise de domínio organizacional na perspectiva arquivística: potencialidade no uso da metodologia DIRKS - Designing and Implementing Recordkeeping Systems". Trata-se de uma carência cuja superação poderia ser priorizada. Muito há para ser explorado nos campos da gestão de programas e dos serviços arquivísticos em suas experiências de implantação. A área de Tecnologia também é carente no PPGCI, acusando percentual bastante inferior ao da média internacional. Como exemplos desses trabalhos, citam-se a dissertação "Sistemas eletrônicos de gerenciamento de documentos arquivísticos: Um questionário para escolha, aplicação e avaliação" e a tese "A preservação de documentos eletrônicos de caráter arquivístico: Novos desafios, velhos problemas" - que abordam essas temáticas pela perspectiva da Tecnologia da Informação e não das funções arquivísticas. Já os temas "Suportes" e "Tipos de arquivo" se restringem a dissertações, como no caso do "Gestão arquivística na era do cinema digital: formação de acervos de documentos digitais provindos da prática cinematográfica". 0 estudo das instituições arquivísticas também é desconhecido pelo PPGCI, embora se trate de um tema relevante em termos internacionais. Ainda há muito a ser pesquisado sobre os arquivos empresariais, eclesiásticos ou, mais especificamente, os arquivos públicos, entre outros temas de natureza institucional.

Nos cenários nacional e internacional, a dimensão mais impactante do Tabela 1 diz respeito à discrepância referente aos problemas particulares dos arquivos e a outros temas. Enquanto na produção internacional esses dois itens dizem respeito a apenas $3,0 \%$ das pesquisas, no PPGCI eles abarcam 45,0\% dos principais temas das dissertações e teses. Acreditamos que há pelo menos dois motivos para isso: o primeiro é a não implementação da política nacional de arquivos; e o segundo é a inexistência de sistemas nacional, estadual e municipal de arquivos, previstos por leis federais, estaduais e municipais há quase três 
décadas, aspectos que despertam o interesse de muitos pesquisadores. Esses são os casos, por exemplo, da dissertação "Arquivos Legislativos: a política pública arquivística em instituições legislativas municipais" e da tese "1a CNARQ: a Conferência Nacional de Arquivos e a construção de uma política nacional para os arquivos brasileiros". Outra razão a ser sublinhada, para explicar a discrepância constatada na Tabela 1, prendese ao protagonismo da Biblioteconomia/Ciência da Informação na constituição e no desenvolvimento do PPGCI. Como resultado disso, há temas de pesquisa que na arquivística internacional são considerados "gerais", dizendo respeito a $1,0 \%$ dessa produção, mas que no caso brasileiro adquirem grande relevância, como, por exemplo: a dissertação "A importância dos estudos de usuários na formação do arquivista" e a tese "O ato colecionador, sobre interfaces entre Arquivologia, Biblioteconomia e Museologia".

\section{Considerações finais}

As diferenciações entre produção nacional e produção internacional, longe de diminuir a importância do PPGCI, mostram que este programa tem uma história própria e que ele não é um simples reflexo ou cópia de experiências internacionais. Ao longo de mais de quarenta anos, o PPGCI constituiu-se em um espaço para promover a capacitação de professores de Arquivologia e de profissionais de arquivos de diversas partes do País, o que, talvez, constitua uma boa chave para compreender a importância nacional dos estudos de caso no Programa. Afinal, muitos trabalhos trataram de experiências e realidades distantes de Minas Gerais.

Além disso, pensar na produção intelectual em Arquivologia, a partir da Universidade Federal de Minas Gerais, exige que se alargue o olhar para outros espaços no próprio campus. No caso dos estudos sobre temas referentes aos objetivos da Arquivologia e à relação entre arquivo e sociedade, é possível vislumbrar o interesse do Programa de Pósgraduação em Estudo Literários, situado na Faculdade de Letras da UFMG, que tem uma linha denominada "Literatura, História e Memória Cultural", a qual aponta em sua ementa o interesse no "Estudo das relações entre literatura, história e memória cultural, com o objetivo de investigar as articulações entre experiência vivida, ficção e organização social, bem como a constituição de acervos enquanto fontes primárias" ${ }^{2}$ Na UFMG, a Biblioteca Central e a Faculdade de Letras, ao longo de suas trajetórias, captaram um vasto e importante conjunto de acervos arquivísticos sobre a vida e a obra de "Escritores Mineiros". A presença de tais conjuntos documentais alarga os espaços de pesquisa e de guarda, assim como estimula as investigações sobre o tratamento, a preservação e o acesso a esses e a outros acervos ou instituições arquivísticas não apenas brasileiras. ${ }^{3}$

\footnotetext{
${ }^{2}$ Disponível em: <http://www.poslit.letras.ufmg.br/pt-br/estrutura-do-programa>. Acesso em: 10 abr. 2018. Destaque nosso.

${ }^{3}$ Cf. FAGUNDES (2001); MAIA (2013); CABRAL (2016).
} 
Um aspecto que talvez explique as poucas pesquisas sobre as temáticas "História dos arquivos" e "Arquivística", no Programa de Pósgraduação em Ciência da Informação da UFMG, refere-se à proximidade com o Programa de Pós-graduação em História. Naquele programa, no mesmo período tratado neste artigo, é possível encontrar pelo menos dois trabalhos sobre o Arquivo Público Mineiro, referentes à constituição do seu acervo e sua organização. ${ }^{4}$ São citados, aqui, apenas exemplos dos espaços contíguos à Escola de Ciência da Informação, porque a proximidade física permite ampliar os canais de interlocuções, levando os temas e objetos de pesquisa da Arquivologia para o debate em áreas afins.

Essas situações, registradas no âmbito da UFMG, apontam similitudes com experiências internacionais, destacadas anteriormente, e demonstram que a proximidade e a interação dos cursos de graduação, e dos programas de pós-graduação, junto a outros (das áreas de ciências da computação, informação, humanas ou sociais). Constata-se, assim, a formação de profissionais atentos à interdisciplinaridade, contribuindo para uma formação aberta a outros olhares investigativos, que se inspira em teorias e métodos de outros campos.

\section{Referências}

BRASIL. Ministério Da Educação. Coordenação de Aperfeiçoamento de Pessoal de Nível Superior. Documento de área: Ciências Sociais Aplicadas I. 2016. Disponível em: <http://capes.gov.br/component/content/article/44-avaliacao/4662ciencias-sociais-aplicadas-i> . Acesso em: 13 de abril 2018.

CABRAL, C. A. Aos leitores, as cartas: proposta de edição anotada da correspondência de Murilo Rubião com Fernando Sabino, Mário de Andrade e Otto Lara Resende. 2016. 362f. Tese (Doutorado em Estudos Literários) - Faculdade de Letras, Universidade Federal de Minas Gerais, Belo Horizonte, 2016.

CENDÓN, B. V.; DUMONT, L. M. Ma. O Programa de Pós-Graduação em Ciência da Informação: trajetória e perspectivas. Perspectivas em Ciência da Informação, Belo Horizonte, v. 20, núm. Esp., p. 1-19, out./dez. 2015.

COUTURE, C. La formation et la recherche en archivistique dans le monde: une étude comparative, Montréal: École de bibliothéconomie et des sciences de l'information, 1999.

COUTURE, C. Education and research in archival science: General tendencies. Archival Science, v . 1, n. 2, p. 157-182, 2001.

COUTURE, C. La formation et la recherche en archivistique : éléments révélateurs de l'état de développement de l'archivistique contemporaine. Synthèse d'un projet de recherché. Archives, v. 33, n. 2, p. 21-52, 2002.

${ }^{4}$ Cf. SILVA (2006); PARRELA (2009). 
COUTURE, C.; DUCHARME, D. Research in Archival Science: a status report. Archivaria, n. 59, p. 41-67, 2005.

COUTURE, C.; LAJEUNESSE, M. L'archivistique à l'ère du numérique: les éléments fondamentaux. Québec: Les Presses de I'Université du Québec, 2014.

FAGUNDES, B. F. L. As efemérides mineiras de José Pedro Xavier da Veiga: as estórias a favor da História. 2001. 147f. Dissertação (Mestrado em Estudos Literário) - Faculdade de Letras/ Universidade Federal de Minas Gerais, Belo Horizonte, 2001.

FONSECA, M. O. Arquivologia e Ciência da Informação: (re) definição de marcos interdisciplinares. 2003. 181f. Tese (Doutorado em Ciência da Informação) - Escola de Comunicação, Universidade Federal do Rio de Janeiro e Instituto Brasileiro de Informação em Ciência e Tecnologia, Rio de Janeiro, 2003.

MAIA, C. C. A imagem inalcançável do todo: coleções, museus, arquivos em Italo Calvino. 2013. 215f. Tese (Doutorado em Estudos Literários) Faculdade de Letras/ Universidade Federal de Minas Gerais, Belo Horizonte, 2013.

MIGLINO, M. A. Avaliação Capes: tendências. Relatório Comissão Especial para Análise do Sistema e Processo de Avaliação da Qualidade da PósGraduação Brasileira. 2017. Disponível em: <http://ppgean.ufsc.br/files/2016/06/Apresenta\%C3\%A7\%C3\%A3oMaria-Angelica.pdf $>$. Acesso em: 3 de abr. 2018.

PAIM, I. A ciência da informação na UFMG: a trajetória do programa de pós-graduação. Perspectivas em Ciência da Informação, Belo Horizonte, v. 5, núm. Esp., p. 105-110, jan./jun. 2000.

PARRELA, I. D. Entre Arquivos, Bibliotecas e Museus: a construção do patrimônio documental para uma escrita da história da pátria mineira 1895-1937. 2009. 415f. Tese (Doutorado em História) - Faculdade de Filosofia e Ciências Humanas, Universidade Federal de Minas Gerais, Belo Horizonte, 2009.

SERVAIS, P.; MIRGUET, F. Introduction. In: SERVAIS, P.; MIRGUET, F. L'archive dans quinze ans: vers de nouveaux fondements. Paris:

Harmattan, 2015. p. 5-14.

SILVA, M. R. História, memória e poder: Xavier da Veiga, o 'arconte' do Arquivo Público Mineiro. 2006. 158f. Dissertação (Mestrado em História) Faculdade de Filosofia e Ciências Humanas/ Universidade Federal de Minas Gerais, Belo Horizonte, 2006.

VIEIRA, A. da S. A Pós-Graduação na EB/UFMG: memória e perspectivas. Revista da Escola de Biblioteconomia da UFMG, Belo Horizonte, v. 19, núm. esp., p. 68-76, mar. 1990. 